\title{
How to Screen for Problematic Cannabis Use in Population Surveys
}

\section{An Evaluation of the Cannabis Use Disorders Identification Test (CUDIT) in a Swiss Sample of Adolescents and Young Adults}

\author{
B. Annaheim ${ }^{a} \quad$ J. Rehm ${ }^{b, c, d} \quad$ G. Gmel ${ }^{a, b}$, e
}

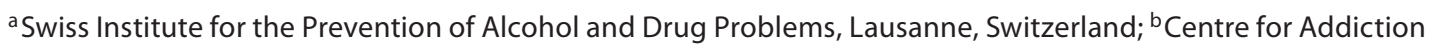
and Mental Health, ' $D$ Department of Public Health Sciences, University of Toronto, Toronto, Ont., Canada;

${ }^{\mathrm{d}}$ Research Institute for Public Health and Addiction, Zurich, ${ }^{\mathrm{e}}$ Alcohol Treatment Centre, Lausanne University

Hospital, Lausanne, Switzerland

\section{Key Words}

Cannabis abuse $\cdot$ Cannabis problems $\cdot$ Cannabis Use

Disorders Identification Test $\cdot$ Dependence $\cdot$ Problematic use $\cdot$ Switzerland

\begin{abstract}
Background/Aims: Cannabis use is a growing challenge for public health, calling for adequate instruments to identify problematic consumption patterns. The Cannabis Use Disorders Identification Test (CUDIT) is a 10-item questionnaire used for screening cannabis abuse and dependency. The present study evaluated that screening instrument. Methods: In a representative population sample of 5,025 Swiss adolescents and young adults, 593 current cannabis users replied to the CUDIT. Internal consistency was examined by means of Cronbach's alpha and confirmatory factor analysis. In addition, the CUDIT was compared to accepted concepts of problematic cannabis use (e.g. using cannabis and driving). ROC analyses were used to test the CUDIT's discriminative ability and to determine an appropriate cut-off. Results: Two items ('injuries' and 'hours being stoned') had loadings below 0.5 on the unidimensional construct and correlated lower than 0.4 with the total CUDIT score. All concepts of problematic cannabis use were related to CUDIT scores. An ideal cutoff between six and eight points was found. Conclusions: Although the CUDIT seems to be a promising instrument to identify problematic cannabis use, there is a need to revise some of its items.

Copyright $\odot 2008$ S. Karger AG, Basel
\end{abstract}

\section{Introduction}

Increasing or high prevalence of cannabis use among younger people raises questions about negative consequences of cannabis use for the individual and his environment. Problematic cannabis use is becoming a challenge for public health, but there is no generally accepted definition of what constitutes problematic use. Usually only general statements, such as the comment that problematic use is that which leads to negative consequences on a social or health-related level [1], can be found. Hence, there is an increasing demand for appropriate instruments to assess problematic use patterns. One instrument to screen for cannabis abuse or dependence in a quick and easy way is the Cannabis Use Disorders Identification Test (CUDIT) [2]. There has been no evaluation of the CUDIT in large-scale general population samples yet, so the present study provides such an evaluation for Switzerland.

Several tools for the assessment of problematic cannabis use exist but they are of varying quality and many lack validation $[1,3]$. In 2003, the CUDIT was constructed by modifying the Alcohol Use Disorders Identification Test (AUDIT) [4], and its validity was examined in a small sample $(n=53)$ of cannabis-using alcohol-dependent outpatients in New Zealand [2]. Taking DSM-IV criteria as the 'gold standard', it was found that the CUDIT was superior to a simple frequency-of-use measure. The cutoff value of eight points, as used for the AUDIT [4], appeared to be suitable in that sample [2]. Two years later, a

\section{KARGER}

Fax +41613061234 E-Mail karger@karger.ch www.karger.com
(C) 2008 S. Karger AG, Basel

$1022-6877 / 08 / 0144-0190 \$ 24.50 / 0$

Accessible online at:

www.karger.com/ear
Beatrice Annaheim

Swiss Institute for the Prevention of Alcohol and Drug Problems SIPA PO Box 870

$\mathrm{CH}-1001$ Lausanne (Switzerland)

Tel. +41 21321 2994, Fax +41 21321 2940, E-Mail bannaheim@sfa-ispa.ch 
German version of the CUDIT was validated in a sample of university students $(\mathrm{n}=171)$. The investigator compared the CUDIT to different external criteria (e.g. to a German version of the Severity of Dependence Scale). She found an ideal cut-off value for cannabis use disorders of between three and five [5].

Discussions about problematic cannabis use are inevitably confounded with general questions about the nature of cannabis-related problems. Every instrument that is chosen to measure problematic cannabis use relies on a 'social construct' [6] of what is seen to be 'normal' and what is not.

However, different experts agree on at least a few points: the scientific literature shows evidence for the impairing effect of cannabis on cognitive functioning, concentration, and on educational and working performance $[7,8]$. Impairing effects during acute intoxication are undoubted, while possible long-term effects of cannabis on cognitive functioning are controversial $[9,10]$. Consequently, using cannabis before work or school is commonly considered to be problematic $[11,12]$. In connection with the impairing effect of cannabis on cognitive functioning and concentration, many recent studies show evidence of the decreased capacities of intoxicated motor vehicle drivers $[13,14]$ and conclude that driving while under the influence of cannabis must be considered problematic [12]. Some studies found a strong correlation between cannabis use and depression [15-17], whereas others did not $[18,19]$. While the causal path from cannabis use to depression is hardly agreed upon [20,21], it is often argued that cannabis use is problematic for people with an unstable mental health condition, or if it is used as a means of self-medication for psychological troubles like depression, desperation, or anxiety $[12,22]$. Cannabis users with coping motives show lower mental health scores, more symptoms of psychopathology, and more psychosocial distress than cannabis users with social motives $[23,24]$. Some researchers have argued that there are advantages to directness when screening for substance use disorders and thus proposed to rely on the concerned persons own general self-evaluation of whether a certain pattern of cannabis use causes them problems [25].

The AUDIT was conceptualized to screen for hazardous or harmful consumption patterns, before dependence and serious harm have occurred [26]. To date, however, the CUDIT was tested for its ability to screen for abuse or dependence only [2]. Thus, the present study measured the CUDIT's ability to screen for problematic cannabis use in a broader sense, including abuse and dependence, but also hazardous and harmful use.

How to Screen for Problematic Cannabis Use in Population Surveys
Accordingly, our study used the above mentioned, agreed-upon concepts of problematic cannabis use to evaluate the CUDIT: smoking cannabis at work/in school, smoking cannabis and driving, depressive symptoms, smoking cannabis to cope, and self-evaluation. Our study examined the screening instrument's psychometric properties and compared it to these concepts in a general population sample of Swiss adolescent and young adults. Additionally, we wanted to determine a suitable cut-off value to discriminate problematic from 'nonproblematic' users.

\section{Method}

Study Design and Sample

The Swiss Cannabis Monitoring Study was commissioned and financed by the Swiss Federal Office of Public Health. It consisted of a market study, a sentinel system (repeated focus groups with experts), and a longitudinal population survey. This survey collected data about amount, social and health consequences of cannabis use, as well as attitudes towards cannabis and its legality. The following analyses were based on the longitudinal survey's first wave, conducted in 2004. The sample consisted of 13- to 29year-old Swiss inhabitants who were able to communicate in German, French, or Italian.

A representative sample of 5,025 adolescents and young adults was randomly drawn, stratified by region (two-stage selection procedure: (1) households, (2) persons within a household), and interviewed by means of computer-aided telephone interviews by the Swiss social research institute 'IBSF'. The questionnaire consisted of 103 items, with almost half dedicated to cannabis (46 items). The response rate was $62 \%$. Within the sample, $593(11.8 \%)$ were actual cannabis users, i.e. they used cannabis at least once during the 6 months preceding the interview. The CUDIT was completed by actual cannabis users, only. Within this subsample of actual users, $64.2 \%$ were male and $35.8 \%$ female; $54.5 \%$ from German, $34.9 \%$ from French, and $10.6 \%$ from Italian speaking regions; $68.8 \%$ were underage (13-18 years old) and $31.2 \%$ were 19-29 years old; mean age was 18.2 years. The younger age group was oversampled to obtain a sufficient proportion of underage cannabis users. The subsample consisted of $12.8 \%$ daily or almost daily users; $31.2 \%$ used cannabis on a weekly, $31.0 \%$ on a monthly basis, and $25.0 \%$ had used cannabis at least once during the last 6 months, but not on a monthly basis.

Variables

CUDIT. The CUDIT consists of 10 Items (appendix 1). On each item, points are distributed according to the given answers and added up to a total CUDIT score. Possible scores can range from 0 to 40 points. The following variables (table 1) are the 'accepted concepts of problematic cannabis use'. These variables are not part of the CUDIT, but might potentially be associated with cannabis-related problems (depressive symptoms) or deal obviously with it (e.g. smoking and driving).

Smoking Cannabis at Work/in School. People who use cannabis were asked how often they use it 'at work or in school'. Possible answers originally ranged from 'often', 'frequent', 'seldom', to 'never', but were dichotomized into 'often/frequent' and 'seldom/never'. 
Table 1. Concepts of problematic cannabis use $(n=593$, total $)$

\begin{tabular}{|c|c|c|c|c|}
\hline Concepts & Questions & $\begin{array}{l}\text { Positive } \\
\text { if answer is ... }\end{array}$ & $\begin{array}{l}\text { Frequency } \\
\%\end{array}$ & $\begin{array}{l}\mathrm{n} \\
\text { (valid) }\end{array}$ \\
\hline $\begin{array}{l}\text { Smoking cannabis } \\
\text { at work/in school }\end{array}$ & $\begin{array}{l}\text { If you use cannabis, how often do you use it ... at work/in school/ } \\
\text { apprenticeship? }\end{array}$ & often, frequently & 7.64 & 589 \\
\hline $\begin{array}{l}\text { Smoking cannabis } \\
\text { and driving }\end{array}$ & $\begin{array}{l}\text { How often, during the past } 6 \text { months, have you been driving a car, } \\
\text { motorbike, moped within } 2 \text { hours after having used cannabis? }\end{array}$ & at least once & 23.55 & 586 \\
\hline $\begin{array}{l}\text { Depressive } \\
\text { symptoms }\end{array}$ & $\begin{array}{l}\text { Do you remember having lived a period during the last } 12 \text { months, } \\
\text { where you felt sad, dejected, uninterested or depressed, that lasted } \\
\text { for } 2 \text { or more weeks? }\end{array}$ & yes & 40.03 & 592 \\
\hline $\begin{array}{l}\text { Smoking cannabis } \\
\text { to cope }\end{array}$ & $\begin{array}{l}\text { If you use cannabis, how often do you use it ... if you are stressed } \\
\text { (or) ... if you feel lonely (or) ... if you are not doing well? }\end{array}$ & often, frequently & 34.66 & 577 \\
\hline Self-evaluation & Did you ever have any problems with cannabis? & yes & 19.46 & 591 \\
\hline
\end{tabular}

Smoking Cannabis and Driving. This variable measured the frequency of driving a motor vehicle within $2 \mathrm{~h}$ after having used cannabis. The five-point scale was dichotomized into 'at least once' during the 6 months preceding the interview or 'never'. Legal age limit for driving a motor vehicle, i.e. a moped, is 14 years in Switzerland. Nevertheless, 13-year-olds were not excluded from the analyses since one third of those in this age group responded positively to the question.

Depressive Symptoms. Interviewed persons were asked if they had experienced a period of 2 or more weeks within the last 12 months, where they felt 'sad, dejected, uninterested or depressed'. Possible answers were 'yes' or 'no'.

Smoking Cannabis to Cope. If cannabis is used 'to deal with stress', 'if feeling lonely', or 'if feeling down' it serves as a coping strategy. The three items were summed up to build an index of 'coping. Each single item was originally measured on a four-point scale. If on at least one of the three items the answer was 'often' or 'frequent', the coping variable scored positive. The final index had two possible values; either 'coping' or 'no coping'.

Self-Evaluation. People were asked if they ever had problems related to cannabis (without specifying what kind of problems). The variable was dichotomous with the possible answers: 'yes' and 'no'.

\section{Data Analysis}

Analyses were performed using SPSS for Windows and MPlus for the confirmatory factor analysis. Missing values on the 10 CUDIT items ranged from 0 (item 1) to 49 (item 2) and were imputed by means of Markov Chain-Monte-Carlo estimates [27] in PRELIS. Imputation involved replacing an incomplete observation with complete information based on an estimation of the true value drawn from observing other cases with similar answering patterns.

We did not take the complex sampling into account, firstly because the primary aim of the study was analytical (associations between variables) and not descriptive (prevalence estimates) [28], secondly because only a subsample was used and not the full sample for which disproportionate weights existed, and thirdly because no sample survey software was available for some of the statistical routines. However, because of the stratified design which is more efficient than a simple random sample, standard errors and therefore confidence intervals should be even more conservative.

First, for all 10 CUDIT items as a whole, mean, standard deviation, median, mode as well as minimum and maximum total scores were calculated. To present the psychometric properties of the single CUDIT items, each item's mean score and standard deviation was reported. To assess the importance of each item ('item difficulty'), the proportion of the mean item to the mean total score, frequency of each item's positive scorings, and the proportion of CUDIT-positive screened individuals if one item was deleted are described in percentages. Confirmatory factor analysis with categorical factor indicators, based on tetrachoric correlation coefficients, was performed to establish the construct validity of the CUDIT as a single factor model. Subsequently, internal consistency of the CUDIT scale was assessed by Cronbach's alpha if an item was deleted. To further assess internal consistency, the corrected item-total correlation was calculated for each item.

Logistic regression analyses were performed to test the CUDIT's ability to identify problematic cannabis use according to the five external criteria. In addition, receiver operating characteristic (ROC) curves were used to test the CUDIT's discriminative ability between problematic and 'nonproblematic' cannabis users and to determine the most appropriate cut-off score for use as an indicator of problematic cannabis use, by taking the accepted concepts as reference, again. ROC curves show the relationship between sensitivity (proportion of true positives) and specificity (proportion of true negatives) according to reference standards across the full range of possible cut-off values. By calculating the area under the ROC (AUC), the ability of the CUDIT to discriminate between problematic and 'nonproblematic' users (according to the five reference concepts of problematic use) was tested. If ROC represents a straight diagonal line, the AUC is 0.5 , which indicates that a test would not discriminate more than by chance. As a general rule, an AUC between 0.7 and 0.8 is considered an acceptable and an AUC between 0.8 and 0.9 an excellent discrimination [29]. As proposed by Hosmer and Lemeshow [29], optimal cut-off values, according to each of the five reference variables, were defined as the point 
Table 2. Psychometric properties of the individual CUDIT items $(n=593)$

\begin{tabular}{|c|c|c|c|c|c|c|c|c|c|}
\hline \multirow[t]{2}{*}{ Item } & \multirow[t]{2}{*}{ Label } & \multicolumn{2}{|c|}{ Basic statistics } & \multicolumn{3}{|c|}{ Importance of the single items (difficulty) } & \multicolumn{3}{|c|}{$\begin{array}{l}\text { Internal consistency } \\
\text { (discriminative power) }\end{array}$} \\
\hline & & $\begin{array}{l}\text { mean score } \\
\text { per item } \\
\text { (points) }\end{array}$ & $\begin{array}{l}\text { standard } \\
\text { deviation } \\
\text { (points) }\end{array}$ & $\begin{array}{l}\text { proportion of } \\
\text { mean item-score } \\
\text { to mean total- } \\
\text { score }^{\mathrm{a}}, \%\end{array}$ & $\begin{array}{l}\text { frequency of } \\
\text { item's high } \\
\text { scoring }{ }^{\mathrm{b}} \text {, } \\
\%\end{array}$ & $\begin{array}{l}\text { proportion of CUDIT } \\
\text { positive }^{c} \text { screened } \\
\text { individuals if item }^{\text {deleted }}, \%\end{array}$ & $\begin{array}{l}\text { confirmatory } \\
\text { factor } \\
\text { analysis }\end{array}$ & $\begin{array}{l}\text { Cronbach's } \\
\text { alpha } \\
\text { if item } \\
\text { deleted }^{\mathrm{f}}\end{array}$ & $\begin{array}{l}\text { corrected } \\
\text { item-total } \\
\text { correlation }\end{array}$ \\
\hline 1 & Frequency of use & 2.08 & 1.12 & 32.40 & 32.38 & 21.25 & $0.77^{\mathrm{e}}$ & 0.66 & 0.55 \\
\hline 2 & Usual hours being stoned & 0.39 & 0.81 & 6.12 & 3.71 & 31.37 & $0.41^{* * *}$ & 0.71 & 0.23 \\
\hline 3 & Stoned for 6 or more hours & 0.63 & 0.94 & 9.83 & 6.75 & 29.51 & $0.72^{* * *}$ & 0.67 & 0.53 \\
\hline 4 & Not able to stop & 0.30 & 0.84 & 4.73 & 5.06 & 31.70 & $0.77^{* * *}$ & 0.68 & 0.49 \\
\hline 5 & Failed to do what expected & 0.28 & 0.70 & 4.34 & 2.70 & 31.53 & $0.53^{* * *}$ & 0.70 & 0.37 \\
\hline 6 & Morning use & 0.25 & 0.74 & 3.84 & 3.37 & 32.21 & $0.71^{* * *}$ & 0.69 & 0.45 \\
\hline 7 & Guilt/remorse & 0.41 & 0.85 & 6.39 & 4.72 & 29.68 & $0.56^{* * *}$ & 0.70 & 0.35 \\
\hline 8 & Memory/concentration problems & 0.72 & 1.04 & 11.22 & 8.77 & 28.50 & $0.71^{* * *}$ & 0.67 & 0.52 \\
\hline 9 & Injuries & 0.26 & 0.98 & 3.99 & 6.41 & 31.37 & 0.13 & 0.74 & 0.07 \\
\hline 10 & Concerned others & 1.10 & 1.79 & 17.14 & 27.49 & 24.79 & $0.59^{* * *}$ & 0.71 & 0.41 \\
\hline
\end{tabular}

${ }^{a}$ Mean CUDIT total-score: $6.42{ }^{b}$ High scoring: if at least three points per item. ${ }^{\mathrm{c}}$ Positive: if at least eight points on the total CUDIT. ${ }^{\mathrm{d}}$ Proportion of positive screened individuals for the total CUDIT: $33.20 \% .{ }^{\mathrm{e}}$ Reference category. ${ }^{\mathrm{f}}$ Cronbach's alpha for the total CUDIT: 0.72 . ${ }^{* * *} \mathrm{p}<0.001$.

where sensitivity and specificity curves cross. The exact crossing points were obtained by means of graphic illustrations.

Finally, the prevalence of problematic cannabis use among all actual users, according to the different calculated CUDIT cutoffs, was computed.

\section{Results}

\section{Psychometric Properties of the CUDIT}

Subjects scored at an average (mean) of 6.4 points on the total CUDIT. Standard deviation was 5.4 and median was five points. The majority of the subjects got one CUDIT point; maximum points reached was 31 .

As indicated in table 2 (column 1) the largest part of the total CUDIT score was contributed by item 1 (frequency of use) followed by item 10 (concerned others). In contrast, the contributions of items 6 (morning use) and 9 (injuries) were the weakest. However, for all but items 1 and 10 , item difficulties were high with rates of positive scoring $<10 \%$ (column 4 ). The proportion of CUDITscreened positive individuals if one item was deleted (column 5) indicated the importance of item 1 again: if this item was deleted, only $21.25 \%$ of all actual cannabis users were screened positive compared to $33.20 \%$ positive screened without deleting any item. A similar decline in positively screened users would appear by deleting item 10. In contrast, item 6 could be deleted with only a small loss in positive screened cannabis users.

Confirmatory factor analysis (column 6) yielded high factor loadings for items 1 and 4 (not able to stop). Item 9 performed very weakly, followed by item 2 (usual hours being stoned) and item 5 . Internal consistency for the total CUDIT score, measured by Cronbach's alpha, was satisfactory (0.72). A modest improvement occurred when item 9 was deleted (column 7). However, without item 1, item 3 (stoned for 6 or more hours) or item 8 (memory/ concentration problems) the internal consistency declined remarkably. Finally, corrected item-total correlations (column 8) were high for items 1 and 3, while they were rather low for items 9 and 2.

\section{Comparison of the CUDIT to External Criteria}

As shown in table 3, all five external criteria were associated to the CUDIT. The strongest association existed between the CUDIT and the user's self-evaluation: individuals who were identified by the CUDIT as problematic users had a more than fivefold risk to ever have had problems with cannabis according to their explicit declaration $(\mathrm{OR}=5.5, \mathrm{p}<0.001)$. The weakest, but still statistically significant, association existed between the CUDIT and the criteria of depressive symptoms $(\mathrm{OR}=1.5, \mathrm{p}<0.05)$.

The AUC was acceptable (i.e. AUC $\geq 0.7$ ) for three out of the five concepts (table 4): best discriminative ability was shown for self-evaluation followed by smoking to cope or smoking at work/in school. However, the discriminative ability of the CUDIT for the other two concepts was insufficient, although still significantly different from the null hypothesis (AUC $=0.5$ ).

In table 5, a list of sensitivity and specificity across the full range of possible cut-off points for each of the con- 
Table 3. Association between CUDIT and five concepts of problematic cannabis use $(n=593$, total)

\begin{tabular}{|c|c|c|c|c|c|c|c|}
\hline \multirow[t]{2}{*}{ Concepts } & \multirow[t]{2}{*}{ Answers } & \multicolumn{3}{|c|}{ According to CUDIT (cut-off 8) } & \multicolumn{3}{|c|}{ Logistic regression } \\
\hline & & $\begin{array}{l}\text { nonproblematic } \\
\text { use, } \%\end{array}$ & $\begin{array}{l}\text { problematic } \\
\text { use, } \%\end{array}$ & $\begin{array}{l}\mathrm{n} \text { (valid) } \\
=100 \%\end{array}$ & $\mathrm{~B}$ & SE B & OR \\
\hline \multirow[t]{2}{*}{ Smoking at work/in school } & often/frequently & 35.6 & 64.4 & 45 & \multirow[t]{2}{*}{1.41} & \multirow[t]{2}{*}{0.32} & \multirow[t]{2}{*}{$4.09^{* * *}$} \\
\hline & seldom/never & 69.3 & 30.7 & 544 & & & \\
\hline \multirow[t]{2}{*}{ Smoking and driving } & at least once & 52.2 & 47.8 & 138 & \multirow[t]{2}{*}{0.82} & \multirow[t]{2}{*}{0.20} & \multirow[t]{2}{*}{$2.27^{* * *}$} \\
\hline & never & 71.2 & 28.8 & 448 & & & \\
\hline \multirow[t]{2}{*}{ Depressive symptoms } & yes & 61.2 & 38.8 & 237 & \multirow[t]{2}{*}{0.41} & \multirow[t]{2}{*}{0.18} & \multirow[t]{2}{*}{$1.51^{*}$} \\
\hline & no & 70.4 & 29.6 & 355 & & & \\
\hline \multirow[t]{2}{*}{ Smoking to cope } & often/frequently & 43.0 & 57.0 & 200 & \multirow[t]{2}{*}{1.67} & \multirow[t]{2}{*}{0.19} & \multirow[t]{2}{*}{$5.34^{* * *}$} \\
\hline & seldom/never & 80.1 & 19.9 & 377 & & & \\
\hline \multirow[t]{2}{*}{ Self-evaluation } & yes & 34.8 & 65.2 & 115 & \multirow[t]{2}{*}{1.70} & \multirow[t]{2}{*}{0.22} & \multirow[t]{2}{*}{$5.50^{* * *}$} \\
\hline & no & 74.6 & 25.4 & 476 & & & \\
\hline
\end{tabular}

Logistic regression $=$ independent variable: problematic cannabis use according to CUDIT $(1=$ yes, $0=$ no $)$. Dependent variables $=$ problematic cannabis use according to five concepts of problematic cannabis use $\left(1=\right.$ yes, $0=$ no). ${ }^{*} \mathrm{p}<0.05,{ }^{* * *} \mathrm{p}<0.001$.

Table 4. ROC curve analyses $(n=593)$

\begin{tabular}{lllll}
\hline Concepts & $\begin{array}{l}\text { Asymptotic } \\
\text { sign. }\end{array}$ & $\begin{array}{l}\text { Area under } \\
\text { the ROC }\end{array}$ & & \multicolumn{2}{l}{ Asymptotic 95\% CI } \\
\cline { 5 - 5 } & & & lower bound & upper bound \\
Smoking at work/in school & 0.000 & 0.740 & 0.668 & 0.812 \\
Smoking and driving & 0.000 & 0.631 & 0.578 & 0.684 \\
Depressive symptoms & 0.004 & 0.569 & 0.522 & 0.616 \\
Smoking to cope & 0.000 & 0.761 & 0.722 & 0.801 \\
Self-evaluation & 0.000 & 0.770 & 0.724 & 0.817
\end{tabular}

${ }^{a}$ If testing difference to null hypotheses (area under the ROC $=0.5$ ).

cepts is presented. Concerning the three concepts for which the CUDIT's discriminative ability was acceptable, the optimal cut-off (i.e. where sensitivity and specificity curves cross) was either eight (smoking at work/in school), seven (self-evaluation) or six (smoking to cope). While there is one third (33.22\%) of problematic users with the cut-off at eight CUDIT points, there would be nearly half of actual cannabis users (44.86\%) defined as problematic users, if cut-off was set with six points.

\section{Discussion}

There is currently no agreed-upon definition of problematic cannabis use that could be used for screening purposes. Comparative studies such as the one conducted by the European Monitoring Centre for Drugs and Drug Addiction [30] commonly use prevalence estimates such as past 30 days use. The lack of an agreed-upon definition is surprising as cannabis can undoubtedly have some negative consequences on physical and mental health, and numbers of cannabis treatment demands have been increasing all over the world [31]. Several indicators for problematic drug use in general, and thus also cannabis, have been discussed, e.g. the 'treatment multiplier' or 'police data multiplier' or just prevalence of regular (daily) use [31]. All these indicators have weaknesses, and a more commonly agreed-on comprehensive indicator would make comparative research and reporting easier.

Additionally, an indicator for problematic cannabis use that could be used before treatment is urgently needed and would be particularly useful to aid, for example, in the design of brief interventions for problematic users that have not yet entered the treatment system. Such users have to be identified by screening. In the alcohol field, an indicator that can be used for both monitoring and 
Table 5. Sensitivity, specificity, and optimal cut-off points, $\%(\mathrm{n}=593)$

\begin{tabular}{|c|c|c|c|c|c|c|c|c|c|c|}
\hline \multirow[t]{2}{*}{ CUDIT score } & \multicolumn{2}{|c|}{ Smoking at work/in school } & \multicolumn{2}{|c|}{ Smoking and driving } & \multicolumn{2}{|c|}{ Depressive symptoms } & \multicolumn{2}{|c|}{ Smoking to cope } & \multicolumn{2}{|c|}{ Self-evaluation } \\
\hline & sensitivity & specificity & sensitivity & specificity & sensitivity & specificity & sensitivity & specificity & sensitivity & specificity \\
\hline 1 & 1.000 & 0.000 & 1.000 & 0.000 & 1.000 & 0.000 & 1.000 & 0.000 & 1.000 & 0.000 \\
\hline 2 & 0.978 & 0.184 & 0.906 & 0.199 & 0.873 & 0.208 & 0.975 & 0.247 & 0.965 & 0.210 \\
\hline 3 & 0.933 & 0.309 & 0.848 & 0.335 & 0.759 & 0.330 & 0.920 & 0.403 & 0.948 & 0.353 \\
\hline 4 & 0.889 & 0.426 & 0.703 & 0.435 & 0.646 & 0.439 & 0.845 & 0.538 & 0.870 & 0.473 \\
\hline 5 & 0.844 & 0.494 & 0.667 & 0.511 & 0.578 & 0.504 & 0.750 & 0.589 & 0.835 & 0.546 \\
\hline 6 & 0.756 & 0.575 & 0.580 & 0.589 & 0.502 & 0.589 & 0.660 & 0.668 & 0.774 & 0.632 \\
\hline 7 & 0.711 & 0.642 & 0.522 & 0.656 & 0.439 & 0.654 & 0.625 & 0.751 & 0.713 & 0.697 \\
\hline 8 & 0.644 & 0.693 & 0.478 & 0.712 & 0.388 & 0.704 & 0.570 & 0.801 & 0.652 & 0.746 \\
\hline 9 & 0.578 & 0.733 & 0.428 & 0.752 & 0.333 & 0.738 & 0.500 & 0.822 & 0.591 & 0.782 \\
\hline 10 & 0.489 & 0.787 & 0.377 & 0.810 & 0.266 & 0.786 & 0.430 & 0.873 & 0.530 & 0.836 \\
\hline 11 & 0.444 & 0.822 & 0.333 & 0.844 & 0.241 & 0.831 & 0.375 & 0.899 & 0.478 & 0.870 \\
\hline 12 & 0.400 & 0.846 & 0.304 & 0.868 & 0.207 & 0.851 & 0.335 & 0.918 & 0.435 & 0.891 \\
\hline 13 & 0.400 & 0.869 & 0.254 & 0.882 & 0.190 & 0.876 & 0.305 & 0.936 & 0.400 & 0.910 \\
\hline 14 & 0.333 & 0.901 & 0.174 & 0.902 & 0.152 & 0.907 & 0.245 & 0.955 & 0.313 & 0.931 \\
\hline 15 & 0.333 & 0.921 & 0.145 & 0.917 & 0.148 & 0.935 & 0.220 & 0.971 & 0.261 & 0.941 \\
\hline 16 & 0.267 & 0.938 & 0.138 & 0.942 & 0.110 & 0.944 & 0.165 & 0.973 & 0.209 & 0.954 \\
\hline $\begin{array}{l}\text { etc. } \\
\text { Optimal }^{\mathrm{a}} \\
\text { cut-off }\end{array}$ & \multicolumn{2}{|c|}{8} & \multicolumn{2}{|c|}{6} & \multicolumn{2}{|l|}{6} & \multicolumn{2}{|l|}{6} & \multicolumn{2}{|l|}{7} \\
\hline
\end{tabular}

a Statistical optimal cut-off is where sensitivity and specificity curves cross [29]. Proportion of positive screened users in the Swiss sample: cut-off $6-44.86 \%$, cut-off $7-38.45 \%$, cut-off $8-33.22 \%$.

screening of problematic alcohol use, namely the AUDIT, is widely accepted and has demonstrated its usefulness in clinical settings as well as in general population surveys in many countries $[26,32]$. A similarly constructed indicator has been suggested for cannabis, the CUDIT.

Psychometric testing, as described in our study, has demonstrated the general usefulness of the CUDIT, but also that there is some room left for improvement as Chronbach's alpha was moderate at 0.72 [33]. Two items had rather low loadings on a unidimensional construct, and their deletion would reduce Chronbach's alpha only very slightly or even increase it. They also correlated poorly with the total scale. Potential reasons for the moderate performance of these items - cannabis related injury (item 9) and usual hours being stoned (item 2) as an indicator for quantity of cannabis use - will be discussed below.

First, though it is widely accepted today that cannabis use can impair driving abilities [12-14, 34], it has also been argued that in practice there might not be any decrease in driving abilities due to the compensation of more cautious driving by cannabis-impaired drivers [31, 35]. Additionally, a triggering effect of cannabis use on violent behavior (leading to injuries) has not been proven.
On the contrary, some studies even suggest a decrease in aggression for cannabis-intoxicated individuals [36, 37]. It might therefore be the case that the injury item that was directly transferred from the Alcohol Use Disorders Identification Test is more appropriate for alcohol than for cannabis-related problems.

Second, it might be challenged whether the number of hours being stoned is an adequate indicator for quantity of cannabis use; the more one is accustomed to cannabis use, the less feelings of being stoned might occur with the same amount of cannabis [38, 39]. However, if that was so, item 3 should have suffered similar difficulties, which was not the case. In addition, it has been shown that quantity of cannabis use is less predictive for dependence than frequency of use [40].

Despite the drawbacks with these two items, the CUDIT total scores were related to external criteria, i.e. five accepted concepts of problematic cannabis use. These clear associations demonstrate the potential of the CUDIT. ROC analysis suggested that a cut-off value of eight (same as the AUDIT [4] or as derived for the CUDIT from a sample of alcohol dependent outpatients [2]) might be too high for a general population screening. Our analyses suggested a cut-off between six and eight. 
Our findings must be interpreted in the face of at least one relevant limitation: The Swiss Cannabis Monitoring Study was primarily conceptualized for epidemiological reasons, not for doing psychometric analyses. Therefore, an approved 'gold standard' - e.g. DSM IV criteria for cannabis abuse and dependence [41] or ICD 10 criteria for harmful use [42] - was not included in the questionnaire. Thus, our evaluation of the CUDIT had to be settled by other references, i.e. items about smoking cannabis at work or in school, smoking cannabis and driving, etc. However, we assessed the usefulness of the CUDIT as a screener for problematic cannabis use, a broader concept than dependence or abuse, and no approved 'gold standard' exists for problematic cannabis use at all.

Based on our findings, we conclude that the CUDIT has the potential to be used as a comprehensive indicator for problematic cannabis use. However, probably due to some items with poor performance, sensitivity and spec- ificity were rather low. There is a need to revise these items and to repeat psychometric testing in order to see whether such a revised screener would perform better.

\section{Acknowledgements}

The Swiss Cannabis Monitoring Study is commissioned and financed by the Swiss Federal Office of Public Health (project 01.001316). The following institutions and researchers collaborated in the Swiss Cannabis Monitoring Study: Swiss Institute for the Prevention of Alcohol and Drug Problems (SIPA), Lausanne (G. Gmel, B. Annaheim); Research Institute for Public Health and Addiction (ISGF/RIHPHA), Zurich (J. Rehm, M. Neuenschwander); Institute of Social and Preventive Medicine (IUMSP), Lausanne (F. Dubois-Arber, S. Arnaud); Institute of Criminology and Criminal Law (ICDP), Lausanne (M. Killias, G.-L. Isenring); Institut für Begleit- und Sozialforschung (IBSF), Zurich (M. Müller).

The authors declare that publication of this paper creates no conflict of interest.

Appendix 1. The Cannabis Use Disorders Identification Test (CUDIT)

Have you used any cannabis over the past 6 months? If YES, please answer the following questions about your cannabis use:

1 How often do you used cannabis?

2 How many hours were you 'stoned' on a typical day when you had been using cannabis?

3 How often were you 'stoned' for 6 or more hours?

4 How often during the past 6 months did you find that you were not able to stop using cannabis once you had started?

5 How often during the past 6 months did you fail to do what was normally expected from you because of using cannabis?

6 How often during the past 6 months did you need to use cannabis in the morning to get yourself going after a heavy session of using cannabis?

7 How often during the past 6 months did you have a feeling of guilt or remorse after using cannabis?

8 How often during the past 6 months have you had a problem with your memory or concentration after using cannabis?

9 Have you or someone else been injured as a result of your use of cannabis over the past 6 months?

10 Has a relative, friend or a doctor or other health worker been concerned about your use of cannabis over the past 6 months?
Answers

never (0), monthly or less (1), 2-4 times a month (2), 2-3 times a week (3), 4 or more times a week (4)

1 or $2(0), 3$ or 4 (1), 5 or $6(2), 7$ to $9(3), 10$ or more (4)

never (0), less than monthly (1), monthly (2), weekly (3), daily or almost daily (4)

never (0), less than monthly (1), monthly (2), weekly (3), daily or almost daily (4)

never (0), less than monthly (1), monthly (2), weekly (3), daily or almost daily (4)

never (0), less than monthly (1), monthly (2), weekly

(3), daily or almost daily (4)

never (0), less than monthly (1), monthly (2), weekly (3), daily or almost daily (4)

never (0), less than monthly (1), monthly (2), weekly (3), daily or almost daily (4)

no (0), yes (4)

no (0), yes (4)

From [2]. Points per answer are indicated in brackets. German, French, and Italian versions of the CUDIT are available from the authors. 


\section{References}

1 Beck F, Legleye S: Measuring cannabis related problems and dependence at the population level. Cannabis in Europe: patterns of use, problems, and public health. Lisbon, European Monitoring Centre for Drugs and Drug Addiction (EMCDDA). In press.

2 Adamson SJ, Sellman JD: A prototype screening instrument for cannabis use disorder: the Cannabis Use Disorders Identification Test (CUDIT) in an alcohol-dependent clinical sample. Drug Alcohol Rev 2003;22: 309-315.

3 Schwoon D, Krausz M: Diagnostik von Störungen durch psychotrope Substanzen; in Stieglitz E-D, Baumann U, Freyberger HJ (eds): Psychodiagnostik in klinischer Psychologie, Psychiatrie, Psychotherapie. Stuttgart, Thieme, 2001, pp 392-404.

4 Babor TF, de la Fuente JR, Saunders JB, Grant M: Audit - The Alcohol Use Disorders Identification Test: Guidelines for Use in Primary Health Care. Geneva, Division of Mental Health, World Health Organization, 1989.

5 Binder K: Validierung des Cannabis Use Disorders Identification Test (CUDIT) an einer studentischen Stichprobe. Epidemiologie des Cannabiskonsums, Substanzstörungen und Drogenwirkungserwartungen bei Erstsemestern; Unveröffentlichte Diplomarbeit, Münster, Westfälische Wilhelms Universität, 2005.

6 Spector M, Kitsuse JI: Constructing Social Problems. New York, Aldine De Gruyter, 1987.

7 Messinis L, Kyprianidou A, Malefaki S, Papathanasopoulos P: Neuropsychological deficits in long-term frequent cannabis users. Neurology 2006;66:737-739.

8 Hall WD, Degenhardt LJ, Lynskey MT: The Health and Psychological Effects of Cannabis Use, 2 ed. Canberra, Commonwealth of Australia, 2001.

-9 Solowij N, Stephens RS, Roffman RA, Babor TF, Kadden RM, Miller M, Christiansen K, McRee B, Vendetti J: Cognitive functioning of long-term heavy cannabis users seeking treatment. JAMA 2002;287:1123-1131.

10 Jager G, Kahn RS, Van Den Brink W, Van Ree JM, Ramsey NF: Long-term effects of frequent cannabis use on working memory and attention: an fMRI study. Psychopharmacology (Berlin) 2006;185:358-368.

11 Thomas G, Flight J, Richard K, Racine S: Toward a Policy-Relevant Typology of Cannabis Use for Canada. Ottawa, Health Canada, Canadian Executive Council on Addictions \& Canadian Centre on Substance Abuse, 2006.

-12 Delile JM: Usage du cannabis: repérage et evaluation des facteurs de gravite. Rev Prat 2005;55:51-63.
13 Laumon B, Gadegbeku B, Martin JL, Biecheler MB; SAM Group: Cannabis intoxication and fatal road crashes in France: population based case-control study. BMJ 2005; 331:1371.

14 Papafotiou K, Carter JD, Stough C: The relationship between performance on the standardised field sobriety tests, driving performance and the level of delta9-tetrahydrocannabinol (THC) in blood. Forensic Sci Int 2005; 155:172-178.

15 Raphael B, Wooding S, Stevens GM, Connor J: Comorbidity: cannabis and complexity. J Psych Practice 2005;11:161-176.

16 Lynskey MT, Glowinski AL, Todorov AA, Bucholz KK, Madden PAF, Nelson EC, Statham DJ, Martin NG, Heath AC: Major depressive disorder, suicidal ideation, and suicide attempt in twins discordant for cannabis dependence and early-onset cannabis use. Arch Gen Psychiatry 2004;61:1026-1032.

17 Degenhardt L, Hall WD, Lynskey MT: Exploring the association between cannabis use and depression. Addiction 2003;98: 1493-1504.

18 Denson TF, Earleywine M: Pothead or pot smoker? A taxometric investigation of cannabis dependence. Subst Abuse Treat Prev Policy 2006;1:22.

19 Monshouwer K, van Dorsselaer S, Verdurmen J, ter Bogt T, de Graaf R, Vollebergh W: Cannabis use and mental health in secondary school children: findings from a Dutch survey. Br J Psychiatry 2006;188:148-153.

20 de Irala J, Ruiz-Canela M, MartínezGonzález MÁ: Causal relationship between cannabis use and psychotic symptoms or depression. Should we wait and see? A public health perspective. Med Sci Monit 2005;11: 355-358.

21 Maharajh HD, Konings M: Cannabis and suicidal behaviour among adolescents: a pilot study from Trinidad. Sci World J 2005;5: 576-585

22 Ries RK: The dually diagnosed patient with psychotic symptoms. J Addict Dis 1993;12: 103-122.

23 Brodbeck J, Matter M, Page J, Moggi F: Motives for cannabis use as a moderator variable of distress among young adults. Addict Behav 2007;32:1537-1545.

24 Zvolensky MJ, Vujanovic AA, Bernstein AM, Bonn-Miller MO, Marshall EC, Leyro TM: Marijuana use motives: a confirmatory test and evaluation among young adult marijuana users. Addict Behav 2007;32:31223130 .

25 Swanum S, McGrew J: Prospective screening of substance dependence: the advantages of directness. Addict Behav 1995;20:205-213.
26 Saunders JB, Aasland OG, Babor TF, de la Fuente JR, Grant M: Development of the Alcohol Use Disorders Identification Test (AUDIT): WHO Collaborative Project on Early Detection of Persons with Harmful Alcohol Consumption. Part II. Addiction 1993;88: 791-804.

27 Congdon P: Applied Bayesian Modelling. Chichester, Wiley, 2003.

28 Groves RM: Survey Errors and Survey Costs. New York, Wiley, 1989.

29 Hosmer DW, Lemeshow S: Applied Logistic Regression, ed 2. New York, Wiley, 2000.

30 European Monitoring Center of Drugs and Drug Addiction (EMCDDA): Annual Report 2006: The State of the Drugs Problem in Europe. Lisbon, EMCDDA, 2006.

31 United Nations - Office on Drugs and Crime (UNODC): World Drug Report 2006. Geneva, United Nations Publications Sales Office and Bookshop, 2006.

32 Ivis FJ, Adlaf EM, Rehm J: Incorporating the AUDIT into a general telephone survey: a methodological experiment. Drug Alcohol Depend 2000;60:97-104

33 Crichton N: Information point: coefficient alpha. J Clin Nurs 1999;8:283.

34 Mura P, Brunet B, Favreau F, Hauet T: Cannabis et accidents de la voie publique: résultats des dernieres études françaises. Ann Pharmac Franç 2006;64:192-196.

35 Smiley A: Marijuana: on-road and drivingsimulator studies; in Kalant $\mathrm{H}$, Corrigall W, Hall WD, Smart RG (eds): The Health Effects of Cannabis. Toronto, Centre for Addiction and Mental Health, Addiction Research Foundation, 1999, pp 171-191.

36 Hoaken PNS, Stewart SH: Drugs of abuse and the elicitation of human aggressive behavior. Addict Behav 2003;28:1533-1554.

37 Myerscough R, Taylor SP: The effects of marijuana on human physical aggression. J Pers Soc Psychol 1985;49:1541-1546.

$>38$ Nocon A, Wittchen HU, Pfister H, Zimmermann P, Lieb R: Dependence symptoms in young cannabis users? A prospective epidemiological study. J Psychiatr Res 2006;40: 394-403.

39 Lichtman AH, Martin BR: Cannabinoid tolerance and dependence. Handb Exp Pharmacol 2005;168:691-717.

40 Chen K, Kandel DB, Davies M: Relationships between frequency and quantity of marijuana use and last year proxy dependence among adolescents and adults in the United States. Drug Alcohol Depend 1997;46:53-67.

41 American Psychiatric Association (APA): Diagnostic and Statistical Manual of Mental Disorders: DSM-IV, ed 4. Washington, American Psychiatric Association, 1995.

42 World Health Organization (WHO): International Statistical Classification of Diseases and Related Health Problems (ICD-10). Geneva, WHO, 2007. 